\title{
Innovation in plastic surgery-why and how?
}

\author{
Joon Pio Hong
}

Editor-in-Chief, Archives of Plastic Surgery

Department of Plastic Surgery, Asan Medical Center, University of Ulsan College of Medicine, Seoul, Korea

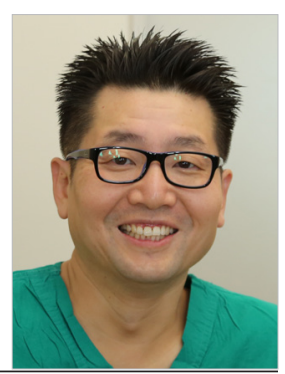

Plastic surgery has always been at the forefront of innovation in the field of medicine. Whether we welcome it or not, we have been challenged to be the problem solvers for other surgical specialties [1]. Problems can be old which had no good solution to existing challenges or new which comes with the continuous evolution of medicine. In order to solve these old or new problems, plastic surgeons have come up with improved or newly designed solutions for problems even thought to be unsolvable. This "Innovation" has been the key to current success of plastic surgery and as Dr. Rohrich states, we must continue innovating to promote the future of our specialty. Innovation is indeed the backbone of our specialty $[2,3]$.

So how do we innovate? What are the key steps for innovation? In my experience, it all starts by asking "why." Why have we done it this way till now? What is the basis for doing it this way? By asking why, we seek evidence and reason behind each surgical solution. You will be amazed to learn how much we do actually lacks solid evidence. Yes, medicine is anecdotal but in the age of science and technology that we live in today, we can do better. At least find evidence or rationale for what we do. "Why" leads to the next step for innovation. The "research" which is finding answers to your question. So many surgeons have similar questions and there are a lot of research behind it. So, we learn from our questions but if there is no solid answer then it is up to you to do the research and at least generate a hypothesis. When you have a good hypothesis after doing research, then it is time to share your hypothesis or to be validated by your peers which leads to the third step for innovation, "communication/validation." Talk with your peers, mentors or even someone on the professional social media. By communicating, you will be surprised how much refined your hypothesis or ideas can be to build a solid rationale. The final and fourth step is to "do it." As Theodore Levitt said, "Creativity is thinking but innovation is doing." As plastic surgeons, we always think of new things but if we do not implement based on solid hypothesis it will never become part of the practice and thus innovation. These four steps have guided me to continuously seek changes for the better. This is not a onetime approach but should be part of your professional habit. See the innovators of our age, they all ask by starting with "why."

The Archives of Plastic Surgery has been expanding while continuing the aim to be the platform and medium for plastic surgeons' innovation $[4,5]$. As Dr. Hallock mentioned, "Yet without innovation, whether appropriate or not often to be first found in the daring and novelty of case reports or small patient series, the fear without them should be that there will be no future new outcomes to study" [6]. While not many major plastic surgery journals publish cases, the Archives of Plastic Surgery journal will continue to bring innovative cases, ideas \& Innovation, and original articles to facilitate communication and validation of innovative ideas, procedures and techniques and continue the tradition of innovation in our field [7]. We look forward to reading your latest innovations that may change the way we practice today with the first case you do.

Finally, I would like to take this opportunity to thank the authors, reviewers, and editors for working together to bring innovations to our field.

\section{NOTES}

\section{Conflict of interest}

Joon Pio Hong is an editorial board member of the journal but 
was not involved in the peer reviewer selection, evaluation, or decision process of this article. No other potential conflicts of interest relevant to this article were reported.

\section{ORCID}

Joon Pio Hong https://orcid.org/0000-0002-6208-9704

\section{REFERENCES}

1. Longaker MT, Rohrich RJ. Innovation: a sustainable competitive advantage for plastic and reconstructive surgery. Plast Reconstr Surg 2005; 115:2135-6.

2. Mathes SJ. Innovation. Plast Reconstr Surg 2007;120:2110-1.

3. Rohrich RJ, Cason RW, Avashia YJ, et al. Evidence-based innovations driving the future of plastic surgery. Plast Reconstr Surg 2021; 147:258-61.
4. Huh S. How journal metrics illustrate the transformation of Archives of Plastic Surgery into an international journal. Arch Plast Surg 2014;41:617-9.

5. Kim YH. Archives of Plastic Surgery's efforts to become indexed in Science Citation Index Extended (SCIE) over the last 3 years. Arch Plast Surg 2019;46:395-6.

6. Hallock GG. Innovations: a dawning of a new age. Arch Plast Surg 2021;48:147-8.

7. Goh T. The innovative journal. Arch Plast Surg 2021;48: 241-2.

Correspondence: Joon Pio Hon

Department of Plastic Surgery, Asan Medical Center, University of Ulsan College of Medicine, 88 Olympic-ro 43-gil, Songpa-gu, Seoul 05505, Korea

Tel: +82-2-3010-3600, Fax: +82-2-476-7475, E-mail: joonphong@amc.seoul.kr

Received: August 25, $2021 \bullet$ Revised: August 29, 2021 • Accepted: August 30, 2021

pISSN: 2234-6163・ eISSN: 2234-6171

https://doi.org/10.5999/aps.2021.01669 • Arch Plast Surg 2021;48:471-472 